Field report

\title{
Alcohol-related morbidity in a rural area in Germany
}

\author{
Katharina Lau and Hans-Joachim Hannich \\ Institute for Medical Psychology, University Medicine Greifswald, Germany
}

(J Rural Med 2016; 11(1): 30-33)

\section{Introduction}

The federal state of Mecklenburg Western Pomerania is located in the north-eastern part of Germany encompassing an area of $23.213 \mathrm{~km}^{2}$ (Figure 1). Mecklenburg Western Pomerania is considered as rural area with 1.599 .138 inhabitants (31.12.2014) corresponding to 69 inhabitants per $\mathrm{km}^{2}{ }^{1}$. In 2014, the unemployment rate was $11.2 \%$ (in comparison: In 2014, the unemployment rate in Germany was $6.7 \%)^{1}$. Besides social problems, providing comprehensive medical care is challenging due to a low number of family practitioners in this area, long distances between patients and health care providers, but also due to the demographic change and an increase in chronic diseases.

After the German reunification in 1990, data showed that life expectancy was substantially lower in the east than in the west, in particular in the northeast ${ }^{2}$. Furthermore, the burden of disease in the German population showed considerable regional variation, e.g. regarding hypertension and diabetes mellitus ${ }^{3,4}$. One hypothesis was that people in the north-eastern part of Germany show more health-related risk factors as unhealthy eating habits, smoking and alcohol consumption. However, scientific data on these questions were lacking and a research network was founded to investigate to what extent the high mortality can be explained by risk factors. The Study of Health in Pomerania (SHIP), a population-based cohort study covering the region of Western Pomerania, was established. Study details are described in detail elsewhere ${ }^{2)}$. The first aim of SHIP is to investigate the prevalence and incidence of common risk factors, subclinical disorders and clinical diseases.

Received: January 31, 2016, Accepted: February 8, 2016

Correspondence: Katharina Lau, Institute for Medical Psychology, University Medicine Greifswald, Walther-Rathenau-Str. 48, 17475 Greifswald, Germany

E-mail: katharina.lau@uni-greifswald.de

This is an open-access article distributed under the terms of the Creative Commons Attribution Non-Commercial No Derivatives (by-ncnd) License $<$ http://creativecommons.org/licenses/by-nc-nd/4.0/> .
For example, the study is focusing on thyroid disorders, diabetes, hypertension and behavioral risk factors as smoking, physical inactivity, unhealthy eating habits and alcohol consumption. The second aim of SHIP is to investigate the complex interactions between risk factors and subclinical and clinical diseases. To achieve these aims, a comprehensive examination program was established including among others a medical interview, laboratory testing, sonographic examinations, and dermatological and dental examinations. The sample comprised of 4308 individuals aged 20 to 79 years.

\section{Alcohol consumption in Western Pomerania}

Data from SHIP revealed that $52 \%$ of the individuals had consumed beer within the last 7 days, $56 \%$ of the individuals had consumed wine and $39 \%$ of the individuals had consumed spirits within the last 7 days. The prevalence of risky drinking, which is defined as drinking above the recommended levels, was $14 \%$. Moreover, the prevalence of

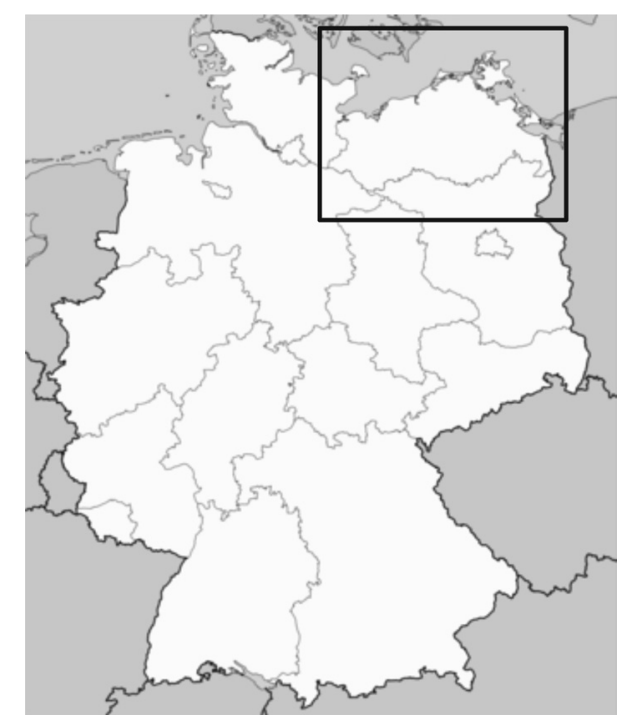

Figure 1 The federal state of Mecklenburg Western Pomerania, Germany. 
Table 1 Characteristics of the study population ${ }^{8)}$

\begin{tabular}{|c|c|c|c|c|c|c|}
\hline & \multicolumn{3}{|c|}{ Males } & \multicolumn{3}{|c|}{ Females } \\
\hline & $\begin{array}{l}\text { No hepatic } \\
\text { steatosis } \\
(\mathrm{n}=1150)\end{array}$ & $\begin{array}{c}\text { Hepatic } \\
\text { steatosis } \\
(\mathrm{n}=707 ; 38.1 \%) \\
\end{array}$ & P-value & $\begin{array}{l}\text { No hepatic } \\
\text { steatosis } \\
(\mathrm{n}=1488)\end{array}$ & $\begin{array}{c}\text { Hepatic } \\
\text { steatosis } \\
(\mathrm{n}=413 ; 21.7 \%)\end{array}$ & P-value \\
\hline Age $(\mathrm{M}, \mathrm{SD})$ & $47.0(32.0,63.0)$ & $56.0(45.0,66.0)$ & $<.001$ & $44.0(33.0,58.0)$ & $60.0(51.0,69.0)$ & $<.001$ \\
\hline Alcohol consumption, g/day (M, SD) & $16.7(29.4)$ & $21.2(27.2)$ & $<.001$ & $6.5(11.0)$ & $3.8(6.4)$ & $<.001$ \\
\hline Binge drinking $(\%)$ & 41.5 & 47.8 & $<.01$ & 19.8 & 10.9 & $<.001$ \\
\hline BMI, kg/m² (M, SD) & $26.4(23.8,28.7)$ & $29.1(26.7,31.8)$ & $<.001$ & $24.8(22.3,28.5)$ & $30.5(27.4,34.4)$ & $<.001$ \\
\hline Physically inactive (\%) & 61.1 & 68.8 & $<.01$ & 59.7 & 74.1 & $<.001$ \\
\hline
\end{tabular}

Lau K, Baumeister SE, Lieb W, Meffert PJ, Lerch MM, Mayerle J \& Völzke H (2015). The combined effects of alcohol consumption and body mass index on hepatic steatosis in a general population sample of European men and women. Aliment Pharmacol Ther 41: 467-476.

excessive drinking, which is defined as a consumption of at least 5 drinks per occasion in the last 30 days, was $43 \%$. Furthermore, a high prevalence of alcohol-related diseases was present in the study population: $38 \%$ of the men and $22 \%$ of the women had hepatic steatosis ${ }^{5,6}$. Regarding overweight and obesity, the median body-mass-index (BMI) was $26.7 \%$. The prevalence of overweight was $39 \%$ and $25 \%$ of the individuals were obese. Likewise, $56 \%$ of the individuals were physically inactive ${ }^{5}$.

\section{Alcohol consumption and hepatic steatosis}

Alcohol consumption and obesity are two main risk factors for hepatic steatosis, which is a disease condition of increasing prevalence in Western countries ${ }^{7}$. The prevalence ranges von $17 \%$ to $33 \%$ in the general population ${ }^{8}$. Previous research on the association between alcohol consumption and hepatic steatosis yielded conflictive results and suggests that moderate alcohol consumption may have a protective effect against hepatic steatosis. Furthermore, there is evidence that the association between alcohol consumption and hepatic steatosis may be modified by obesity ${ }^{8}$. But, data from individuals of Caucasian origin on this topic are scarce. Using data from SHIP we aimed to investigate (a) the association between average daily alcohol consumption and hepatic steatosis and (b) the combined effect of average daily alcohol consumption and BMI on hepatic steatosis.

\section{Measures}

o Medical interview:

- Sociodemographics

- Behavioral risk factors

- Alcohol consumption (grams per day, binge drinking)

o Somatometry: Body height and weight to calculate the BMI

o Sonography to define hepatic steatosis

\section{Results}

Among the study population, $38.1 \%$ of the male and $21.7 \%$ of the female individuals had hepatic steatosis. Both men and women with hepatic steatosis were older, had a higher BMI and were more often physically inactive than individuals without hepatic steatosis (Table 1). Men with hepatic steatosis had higher average daily alcohol consumption and reported more often binge drinking compared to men without hepatic steatosis. We did not find this pattern in the female study population (Table 1).

We analyzed the dose-response relationship between average daily alcohol consumption and hepatic steatosis using logistic regression analysis. In men, our data showed a dose-response relationship between average daily alcohol consumption and hepatic steatosis starting with a consumption of 20 grams per day (Table 2). In women, average daily alcohol consumption was not associated with hepatic steatosis (Table 2).

Furthermore, we investigated the combined effect of average alcohol consumption and BMI on the likelihood of having hepatic steatosis. BMI was classified according to the recommendations of the World Health Organization as normal weight, overweight and obesity. We performed logistic regression analyses and demonstrated that BMI enhanced the effect of average daily alcohol consumption in men (Figure 2). In women, only obesity enhanced the effect of average daily alcohol consumption on hepatic steatosis (Figure 3).

\section{Conclusion}

Taken together, the present data demonstrate a high prevalence of alcohol drinking and overweight/obesity in the region of Western Pomerania giving support to the idea that the population is a population "at risk". Subsequent morbidity was evident. We found a dose-response relation- 
Table 2 Dose-response relationship between average daily alcohol consumption and hepatic steatosis ${ }^{8)}$

\begin{tabular}{lcc}
\hline & OR & $95 \% \mathrm{CI}$ \\
\hline Alcohol consumption (g/day) - men $^{\dagger}$ & & - \\
$0 \mathrm{~g}$ & 1 & -19 \\
$10 \mathrm{~g}$ & 1.53 & $0.85-1.66$ \\
$20 \mathrm{~g}$ & 2.03 & $1.15-2.05^{*}$ \\
$40 \mathrm{~g}$ & 2.18 & $1.61-2.94^{*}$ \\
$60 \mathrm{~g}$ & 2.24 & $1.62-3.10^{*}$ \\
$80 \mathrm{~g}$ & & $<0.001$ \\
Overall $P$-value & & \\
Alcohol consumption (g/day) - women & & \\
$0 \mathrm{~g}$ & 1 & - \\
$5 \mathrm{~g}$ & 0.72 & $0.52-0.98^{*}$ \\
$10 \mathrm{~g}$ & 0.67 & $0.46-0.98^{*}$ \\
$20 \mathrm{~g}$ & 0.65 & $0.43-0.98^{*}$ \\
$40 \mathrm{~g}$ & 0.65 & $0.34-1.23$ \\
Overall $P$-value & & 0.147 \\
\hline
\end{tabular}

Data are given as odds ratio (OR) with $95 \%$ confidence interval (CI). Alcohol consumption was modeled by restricted cubic splines with four knots $\left(5^{\text {th }}, 50^{\text {th }}, 65^{\text {th }}\right.$, and $95^{\text {th }}$ percentile $)$ in a logistic regression. ${ }^{\dagger}$ adjusted for age, body mass index and HbA1c. ${ }^{*}$ adjusted for age, body mass index, HbAlc and menopausal status.

Lau K, Baumeister SE, Lieb W, Meffert PJ, Lerch MM, Mayerle J \& Völzke H (2015). The combined effects of alcohol consumption and body mass index on hepatic steatosis in a general population sample of European men and women. Aliment Pharmacol Ther 41: 467-476.

ship between average daily alcohol consumption and hepatic steatosis and demonstrated that overweight and obesity increased the effect of average daily alcohol consumption on hepatic steatosis. The present findings underline the necessity to implement population-based interventions to reduce risk factor prevalence and subsequent morbidity. When planning such interventions, it is necessary to consider regional characteristics, e.g. social problems which are related to risky health behavior. Schools, working places, offices and primary care practices display suitable settings for primary prevention.

This article was presented orally on the International Congress on Rural Health held in Lodi, Italy during September 08-11, 2015.

\section{References}

1. Stastisches Jahrbuch Mecklenburg-Vorpommern. 2015: Statistisches Amt Mecklenburg-Vorpommern.

2. Völzke H, Alte D, Schmidt CO, et al. Cohort profile: the study of health in Pomerania. Int J Epidemiol 2011; 40: 294-307. [Medline] [CrossRef]

3. Schipf S, Ittermann T, Tamayo T, et al. Regional differences in the incidence of self-reported type 2 diabetes in Germany: results from five population-based studies in Germany

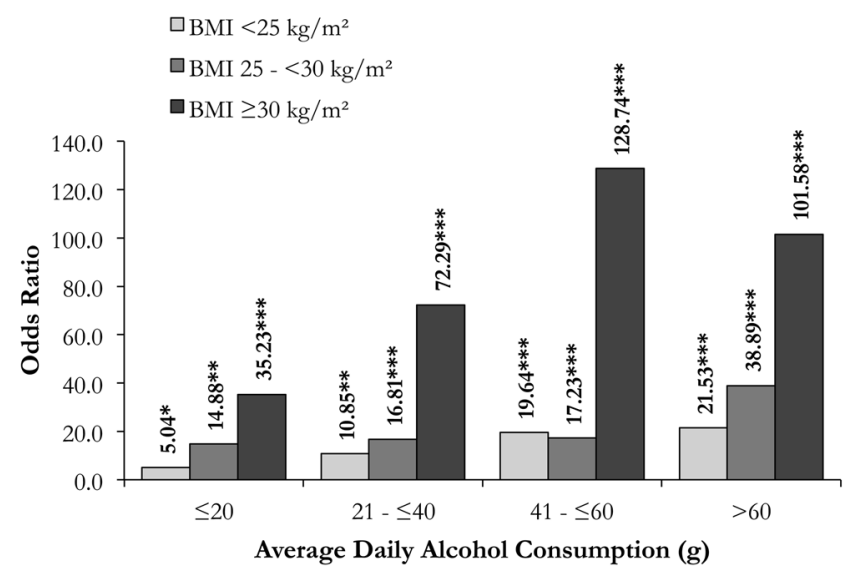

Figure 2 Combined effect of average alcohol consumption and bodymass-index on the likelihood of having hepatic steatosis in the male study population ${ }^{8}$. Adjusted logistic regression odds ratios of men having hepatic steatosis. Analyses are adjusted for age and HbA1c. $* * * \mathrm{p}<.0001, * * \mathrm{p}<.001, * \mathrm{p}<.05$ compared to current abstainers and normal weight individuals.

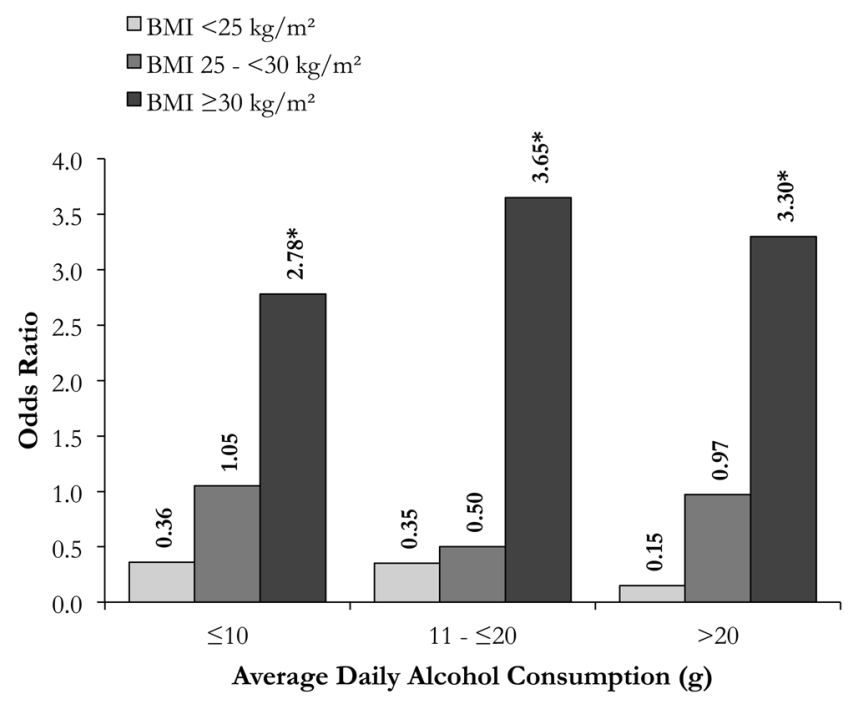

Figure 3 Combined effect of average alcohol consumption and bodymass-index on the likelihood of having hepatic steatosis in the female study population ${ }^{8}$. Adjusted logistic regression odds ratios of women having hepatic steatosis. Analyses are adjusted for age, HbA1c and menopausal status. ${ }^{*} \mathrm{p}<.05$ compared to current abstainers and normal weight individuals.

(DIAB-CORE Consortium). J Epidemiol Community Health 2014; 68: 1088-1095. [Medline] [CrossRef]

4. Meisinger C, Heier M, Völzke H, et al. Regional disparities of hypertension prevalence and management within Germany. J Hypertens 2006; 24: 293-299. [Medline] [CrossRef]

5. Völzke H, Ittermann T, Schmidt CO, et al. Prevalence trends in lifestyle-related risk factors. Dtsch Arztebl Int 2015; 112: 
185-192. [Medline]

6. Baumeister SE, Meyer C, Carreon D, et al. Alcohol consumption and health-services utilization in Germany. J Stud Alcohol 2006; 67: 429-435. [Medline] [CrossRef]

7. Völzke H. Multicausality in fatty liver disease: is there a rationale to distinguish between alcoholic and non-alcoholic origin? World J Gastroenterol 2012; 18: 3492-3501. [Medline]
[CrossRef]

8. Lau K, Baumeister SE, Lieb W, et al. The combined effects of alcohol consumption and body mass index on hepatic steatosis in a general population sample of European men and women. Aliment Pharmacol Ther 2015; 41: 467-476. [Medline] [CrossRef] 